\title{
The Service Industry and the "Moment of Truth": The Quest for the Holy Grail
}

\author{
By Sam Sarpong*
}

\begin{abstract}
Organisations are now seeking to drive corporate performance by maximising the value of their customer relationship. However, beyond this, many companies often fail to appreciate the importance of developing specific, well-defined and integrated business processes focused on the customer. The paper explores this phenomenon by looking at service encounters. It notes that service encounters are much more likely to be delivered within a condition that has a supportive management culture and which recognises the need for delegation of authority and an adherence to customer service standards. This, it reckons, calls for a customer-oriented management philosophy which is the key to gaining competitive advantage. The paper, therefore, identifies and provides an approach to management that seeks to achieve new objectives with a greater consistency of both internal and external relationships. One key contribution of this paper is its enunciation of the importance of "moments of truth". Secondly, it highlights the antecedents which shape customer experience through extensive review of existing literature.
\end{abstract}

Keywords: Customer Care, Competitive Advantage, Empowerment, Moment of Truth, Service Encounter.

\section{Introduction}

The growing importance of the service sector in almost every economy in the world has created a significant amount of interest in service operations (Morrar 2014, Baum 2002, Cowell 1984). Service industries now account for $50 \%$ of the gross domestic product of the USA and many European countries and over one quarter of the worlds trade (Winstead 2000). In India, the services sector has made rapid strides in the past decade and a half to emerge as the largest and one of the fastest-growing sectors of the economy (India Brand Equity Foundation 2016).

In recent years, more jobs have been created in services than in any other sector and the companies in the services sector are expected to be key drivers to reduce unemployment from its record levels (Global Services Forum 2013).

Several reasons account for the growth of the service sector. These include growing affluence, urbanisation, technological development, development of markets, opening up of economies, the demand for intermediate and final consumer services, among others. A range of studies reviewed by Francois and Hoekman (2010) has shown that service sector productivity is a key driver of aggregate productivity growth differences across developed economies. This view is also shared by Baum (2002).

\footnotetext{
${ }^{*}$ Lecturer, University of Mines and Technology, Ghana.
} 
However, in spite of the enormous benefits that the sector offers, there seem to be a snag in terms of managing it, especially within the hospitality field. The hotel industry, in particular, is confronted with numerous challenges in the management of service encounters. Good or bad experiences entail certain perceptions of the encounter that could either lead to a gain or loss of guests. Although many in the hospitality industry claim to have customer care programmes (Kotler et al. 2003), the vast majority are at best partially successful in that (Lilja and Wiklund 2006).

Foremost amongst these is that, the majority of approaches are often prescriptive packaged solutions, which are simply not flexible enough to be "owned" by the employees and managers (Sarpong 2015). Quite pertinent too is that, organisational inertia, misconceptions about what customer care is all about and even staff perception of poor services by their own companies have tended to affect the effectiveness of customer care (Baum 2002). Consequently, finding a formula to manage the service sector profitably has become akin to a quest for the Holy Grail (Irons 1994).

In today's marketing environment, an increasingly important source of competitive advantage is the way companies are able to service customers (Payne et al. 2003). Fortunately, many management teams have realised that to achieve their success, they have to develop a service culture of which they must be an integral part. In line with this, Irons (1994) advocates for a holistic, crossfunctional approach to service, which he says, should be based on a deeply held, but simply expressed set of objectives and values and the willingness to see the customer as somebody more than just a target for sales.

But what sort of measures can service firms take in ensuring that service encounters are well managed? What are the key interactions that create value in a service organisation and how does one exceed customer expectations?

The paper explores these fundamental questions. It draws on studies the author conducted on the service industry in South Wales, UK in 2006 (Sarpong 2007), and subsequently in Ghana in 2015 which have since been scaled with secondary information obtained in the last few years (Sarpong 2015). Particularly, the paper examines the unique challenges of service encounters otherwise known as the "moment of truth" and the way they are managed in the hotel setting. It analyses the key factors that make for the long-term success of service enterprises and provides a framework for debating and evaluating service initiatives within the hotel industry.

The paper is organised into five sections. Section one provides an introduction to the issue under review. This is followed by the theoretical underpinnings which explain key concepts that frame the paper. It then provides a framework for debating and evaluating service initiatives within the hotel industry. The discussion section follows after this. The main conclusions are then presented in the concluding part. 


\section{Literature Review}

Many organisations within the service sector today are seeking and making use of various enhancement programmes to improve their operations performance in an attempt to hold competitive success (Smith and Wheeler 2002). The bid to win customer loyalty is, according to Smith and Wheeler (2002), in recognition of the importance that is attached to the consumer today. The competitive success of any organisation ultimately depends on customer satisfaction, which is also determined critically by the customer experience which the service operations are able to maintain (Hartline et al. 2003). Smith and Wheeler (2002), in supporting this stance, claim the service experience that companies deliver to their customers, through every interaction, direct and indirect, says more about their brand than the entire advertising one could possibly buy.

Undoubtedly, service is a strategic concern. As such, the vision of a business has to be firmly rooted in the customers and their perceptions of what is important. The vision is realised at the interaction or encounter stage and it is necessary to have this vision at the centre of the organisational planning. Explicit in this is that, service quality can be well addressed within a condition that ensures collective responsibility with both management and workers striving to achieve the objectives of the organisation.

Lovelock and Wright (2002) have acknowledged the important role workers play in the delivery of quality service and have indicated that any service encounters staff have with customers, greatly affect perceptions of service.

\section{Service Encounters}

A "service encounter" is often referred to as the period of time during which a consumer directly interacts with a service (Payne et al. 2003). This interface between customers and the service provider is also referred to as, the "moment of truth". The quality of service encounters is frequently determined by the actions of front-line staff, whose experience and commitment may be limited and whose attitudes may vary from one encounter to another (Lewis and McCann 2004).

Considerable studies have been done on service encounters over the years by leading writers and academics. Related research efforts have made a great contribution to both academic explorations and practical applications in service operations improvement. Many scholars Scott et al. (2009), Blomqvist et al. (2002), Paraskevas (2001), Baron and Harris (1995), Irons (1994), Whiteley (1991) have written extensively on the issue. Some research works have concentrated on the exchanges that take place between contact personnel and customers and to some extent those that take place between customers (Bradley et al. 2010, Meyer and Schwager 2007, Baron and Harris 1995). Baron and Harris (1995), for instance, have emphasised the important role that customer exposure to other customers does to the reputation of a service organisation. Significantly, what customers discuss, their concerns, including complaints, 
whilst having an interaction with other customers, also have a huge bearing on the operations of the service sector in the same way as the visible elements of the service operating system, i.e. employees and the physical facilities.

The customer-employee interactions have also been an important side of the service experience of customers which have been delved into in many studies, albeit in different dimensions. Some research works have also established that good service encounters accumulated over time tend to reinforce a long-term exchange relationship between customers and organisations (Smith 2003, Smith and Wheeler 2002). For instance, Czepiel (1990) viewed several discussions on service encounters and stated that service encounters are characterised by their purposiveness, the motivation of the provider and their ability to allow people who do not know each other to interact in ways that transcend the barriers of social status. A clear example of this is a case in which front-line staff serves a celebrity.

A study by Söderlund and Julander (2006) on the physical attractiveness of the service worker and its effect on the customer in the "moment of truth" addressed a gap in existing literature on the effects of physical attractiveness. They assessed if the service worker's physical attractiveness has an impact on customer satisfaction in the "moment of truth". The study addressed the extent to which the customer's emotions contribute to this impact. Bitner (1992), meanwhile, also explored the impact of physical surroundings on customers. Subsequently, a framework for understanding the physical environment-user relationships in service organisations was proposed. According to Bitner, customers and employees perceive the environment holistically, as a composite of some dimensions. Available literature also provides service quality measurements with service encounters (Juwaheer 2004, Parasuraman et al. 1988).

\section{Defining the "Moment of Truth"}

In service management literature, the term "service encounter" has been widely used to indicate the contact situation between service customer and service provider. This service contact is often labelled as the "moment of truth" (Zeithmal and Bitner 2003, Albrecht 1988). Many writers Zeithmal and Bitner (2003), Gronroos (1990), Carlzon (1987), Normann (1984) have termed these encounters as the "moment of truth", because it is what happens during these encounters that form the basis of how consumers will judge the business.

Smith (2003) says the "moment of truth" occurs in the relationship when customers experience what organisations have to offer. Explaining further, Smith (2003) indicates that this encounter is when an organisation and the product or service it provides, meets face to face with the customer - the point where a potential customer becomes an actual customer. The outcome of this often determines whether the guest will visit a particular place again or not. Since service encounters are the consumer's main source of information for conclusions regarding quality and service differentiation, no marketer can afford to leave the service encounter to chance (Payne et al. 2003). 
The basis for the description of service encounters as "moments of truth" stems from the idea that the characteristic attributes of services, intangibility and customer participation in the service production process, cause a particular relevance of service contact situations, which in turn affect the service customers' quality perception (Strauss and Mang 1999). A customer may form an impression about the quality of a dentist's work, for example, from a brief conversation with another patient in the waiting room or simply from a glance at the wallpaper in the surgery (Woodruffe 1995). Irrespective of the nature of and length of the contact, each "encounter" represents an important "moment of truth" for the customer. Hence, as a consequence of the intangibility, services are characterised by a high share of "experience qualities" (Strauss and Mang 1999). Incidentally, the quality of service encounters is frequently determined by the actions of front-line staff, whose experience and commitment may be limited and whose attitudes may vary from one encounter to another (Lewis and McCann 2004).

\section{The Moment of Truth and the Hotel Industry}

The term "moment of truth", as has been explained, underlines strongly the uniqueness and the importance of every encounter between the customer and the service provider. It is therefore "the foundation or building block for customer satisfaction and service quality" (Zeithmal and Bitner 2003: 99). Jan Carlzon, former president of Scandinavian Airlines, is credited with originating the concept of "moments of truth". Carlzon (1987) took an airline that was failing and turned it around to be one of the most respected airlines in the industry. His strategies mainly dwelt on focussing on the customer, encouraging risk-taking, delegating more authority to front-line employees and eliminating vertical levels of hierarchy for a more horizontal organisation that bear the hallmarks of entrepreneurial management and the pursuit of excellence. He determined that the first 15 second encounter between a passenger (customer) and his front-line people (employees) set the tone or image of the entire company in the mind of that customer. The key, therefore, was to ensure that every "moment of truth" proved a positive one for the customer.

The experience of front-line staff to the delivery of quality service and ultimately, customer satisfaction is widely accepted (Walls et al. 2009, Mahesh 1988). Carlzon (1987) described the "moment of truth" as every point of contact between the customer and front-line staff of the company, thus applying it to every contact, however seemingly trivial, that a customer has with a staff member or agent of the company in question. Although in themselves these are relatively small incidents, "moments of truth" are make or break occasions when an organisation has the opportunity to disappoint the customer by failing to meet expectations or can get it right by matching those expectations or even excel by exceeding expectations (Zeithmal and Bitner 2003, Baum 1997). 
On his part, Baum (1997) argues that from an organisational perspective, while it may be gratifying to exceed expectations, the key objective in the management of the front-line zone must be consistency in meeting customer expectations and minimisation of the occasions when customers are disappointed. In line with that, Pullman and Gross (2004: 556) have argued that "effective experiential design creates loyalty when the service provider relies on its employees and customers to enact a shared identity and emotional connection during the customer's experience".

Incidentally, the level of control and standardisation of service is not feasible as services tend to vary as a result of different situations. In this context, one cannot easily anticipate the nature and outcome of the "moment of truth" which the guest will experience.

In the hotel business, the following interfaces are deemed as "moments of truth":

- when one calls to make a reservation for a room for instance,

- when one arrives at the hotel and checks in with his bags,

- when one goes inside and picks up a key,

- when one is greeted at the reception,

- when one is taken care of at the hotel and later when one is greeted at one's destination.

There are good "moments of truth" and bad "moments of truth". The good "moments of truth" could be categorised as moments of magic whilst the bad ones are often seen as moments of misery. A customer having a moment of misery (i.e., delayed flights and having to turn late at the hotel) could be made to feel more than welcomed at the hotel. It could turn the customer's mood around. This, in essence, has been the hotel's moment of magic. Such an opportunity can be used to show how good an organisation is. This could go a long way to help in building long-term customer loyalty and total customer satisfaction.

\section{The Dynamics of the Service Encounter in the Hotel Setting}

The experience of the guest in a hotel setting is both highly intense and intimate in the interaction that takes place within those providing the services. For most hotel guests, their interactive experience is with the industry's frontline staff, generally those who have the lowest status and are the least trained and the poorest-paid employees of the company (Baum 2002).

Czepiel et al. (1985) have identified a number of distinguishing characteristics of service encounters. According to them:

- Service encounters are purposeful, i.e. a customer calling a waiter to his table for advice.

- Service providers generally for their part are not generally altruistic, i.e. they are providing a service because they are being paid to do so. 
- In most encounters, task related information exchange dominates.

- Service encounters are "limited in scope", with the scope of exchange being restricted by the nature and content of the service to be delivered.

- The roles played by the service provider and the client in the encounter are generally well defined and understood by both parties.

- There is a kind of "stranger" relationship, i.e. prior acquaintance of participants is not required.

- There is a degree of role ambiguity or piquancy to the interaction, i.e. people with different social status is able to come into contact as a basis to either deliver or receive a service.

\section{Adopted Theoretical Model}

One way to explore the dynamics of service encounters between guests and hotel staff is to divide an encounter into its typical stages. Bitran and Lojo (1993) developed a framework for analysing service encounters consisting of six stages, arguing that while service encounters will be unique for client and service provider, such encounters tend to possess the common themes illustrated in Figure 1.

The framework is used here in to discuss the ways in which expectations, perceptions and evaluations are formed by guests of the services as well as the obligations of hotel staff in meeting these.

Figure 1. Typical Stages of a Service Encounter

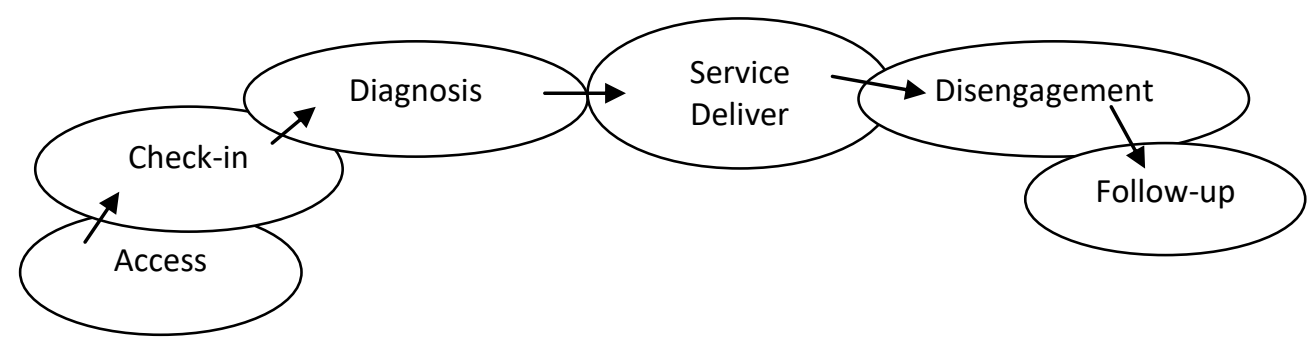

Source: Adapted from Bitran and Lojo (1993).

Access to Hotel or Staff

This is the first stage of the process in which the guest makes an initial contact with hotel personnel. It could have been made on phone, fax or done personally by going to the hotel. If access to the hotel is difficult, then the potential guest may decide not to proceed and might go somewhere else. The more accessible the hotel, the more likely it is that the potential guest will progress to the subsequent stages of the service encounter. A number of factors generally affect the accessibility. These include the location of the place, reliability of staff and quality of services, among others. Once access has been dealt with, the next stage is the check-in. 


\section{Check-in}

The check-in stage is where the actual interaction begins. It is the stage where the physical presence of the guest is made. This establishes the nature of the service the customer requires. At this stage, it is important for the hotel staff to make prompt personal contact with the guests to let them feel welcome and to advise them of any action that will be initiated to meet their requirements. Staff at this point must be skilled at forming good interpersonal relations. They must also be able to establish the purpose of the encounter and be knowledgeable as to how services should be rendered. Enquiries should be treated with prompt attention.

\section{The Diagnosis Stage}

During this diagnosis stage, the front-line staff engages the guests to establish their actual requirements. At this stage, it is pertinent that a guest, who is assessed to be fearful of heights, for instance, can be given a place where he or she might be more comfortable. A special adaptation could be made for a guest who might not want a particular room. Good communication skills are needed at this stage. Staff must be good listeners in order to fully appreciate the concerns of guests. Once the customer's requirements have been identified, the process of service delivery can commence with the hotel staff providing the customer with the package he or she needs.

\section{Service Delivery}

Service delivery could be completed during the meeting with the guest. It could also be spread over a series of encounters especially if the guest wants to eat at the hotel's restaurant, join in at the drinking bar or request for room service. Generally, if staff's interpersonal skills or service attitude cause difficulties with the guests, then the service delivered would generally be considered less than satisfactory.

\section{Disengagement}

The check-out or disengagement stage closes the service encounter. Previous misunderstandings can be identified and corrected especially through customer information made available on forms left in rooms like guest comment cards. Whilst first impressions are important, so too are last impressions since they can help foster close ties with departing guests.

\section{Follow-up}

The follow-up stage is usually initiated by the hotel. It could be a followup questionnaire seeking some feedback on the services provided. This stage 
should identify dissatisfied guests and their reasons for that and much should be done about the causes of the dissatisfaction.

The six stages described are progressive. It is the accumulative effect that will ultimately determine the guest's overall evaluation of the service quality provided by the hotel. All stages should create a positive impression. If mistakes or problems occur, they should be dealt with promptly.

The encounters between customers and hotel staff should be considered vital by both parties, especially as these encounters lay the foundation for and shape hotel operations. They are vital, because customers rely on hotels for the necessary services. Hotels, in turn, rely on customers to generate sales and keep themselves in business. A process of mutual interest exists, characterised by encounters and "moment of truths". Incidentally, the management of the guest-staff relationship remains one of the most difficult and contentious areas within the development and enhancement of the hospitality industry, in particular and service standards generally. As often the case, the level of control and standardisation of service is generally not feasible with respect to the different situations that tend to arise. However, it is important to attempt to manage the situation to ensure a much better perception of the organisation.

When "moments of truth" go un-managed, the quality of service regresses to mediocrity (Albrecht and Zemke 1985). In order to stem the tide, front-line staff needs to be given the power to take decisions that would impact positively on the organisation. Towards this end, the management of the "moments of truth" cycle requires a shift from the traditional control-based supervision and management to a more flexible organisational structure. As depicted in Figure 2, the traditional approach to managing relationships within an organisation can be seen to operate on a hierarchical basis. In addition it shows the value of guests and the important role that front-line staff provides hence the prominence accorded them in the scheme of things.

Figure 2. Traditional Management Hierarchy (TMH) and Inverted Management Structure (IMS)

TMH

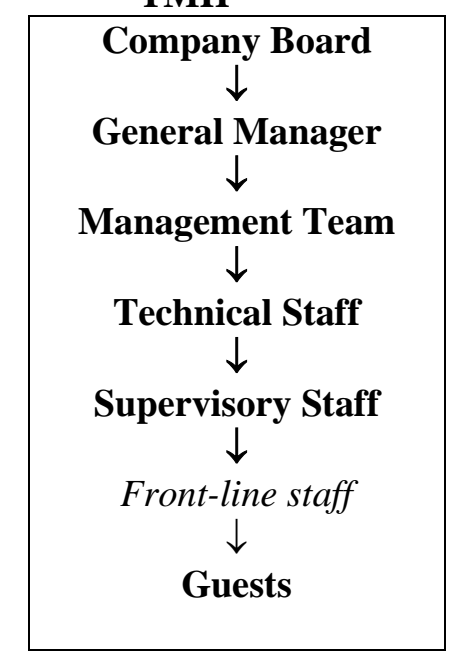

Source: Adapted from Mahesh (1988).

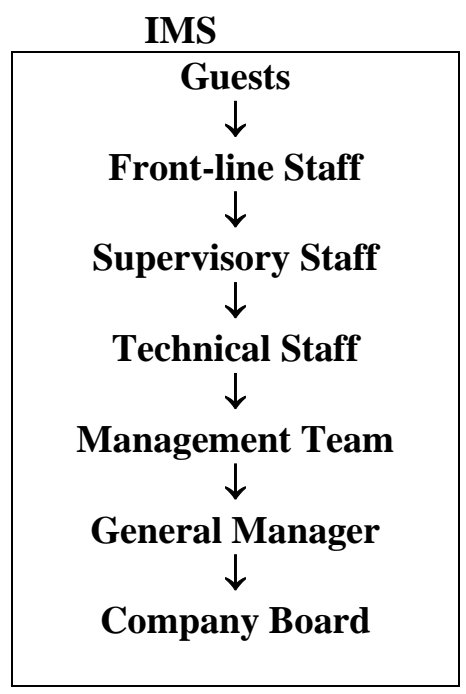




\section{The Traditional Management Hierarchy (TMH)}

The decision making process in Figure 2 is at the level of the senior management. The customer contact zone is figuratively and frequently, literally adrift at the bottom. The organisational structure reflects on the type of relationship prevailing. Management personnel are not available to interact with guests.

\section{The Inverted Management Structure (IMS)}

In contrast, the inverted management structure in Figure 2 demands an approach to management that is not control-based, but is designed to facilitate the working of the operational staff. Management is there to assist front-line colleagues to provide a better service to guests at the point of contact. This can ensure a superior service, which in turn, enhances the competitive position of a hotel and also increases the likelihood that repeat custom will be generated.

\section{Discussion and Implications of the Model for the Hospitality Industry}

From the fore-going, it is evident that service quality is much more likely to be delivered within a condition that has a supportive management culture and which recognises the need for delegation of authority and an adherence to customer service standards (Pullman and Gross 2004). This service quality can be achieved through a sustainable human resource management model. This model should seek to identify the human conditions necessary to overcome the hospitality industry's key issues such as high attrition, poor career commitment and its relative bad image from an employment perspective (Ekinci et al. 2008, Pullman and Gross 2004, Baum 2002). Putting this in a better perspective, what it means is that a dissatisfied worker cannot bring himself or herself up to perform an efficient or effective task. That is why is important to ensure workers are well catered for in order for them to perform their tasks diligently (Sundaram and Webster 2000).

Effective management of the service encounter involves understanding the often complex behaviours of employees that can distinguish a highly satisfactory service encounter from a dissatisfactory one and then training, motivating and rewarding employees to exhibit those behaviours (Ekinci et al. 2008, Baum 2002, Bitner et al. 1990). Writers like Ekinci et al. (2008), Schneider and Bowen (1993), Kelley (1993), and Bitran and Hoech (1990), have all explored the issue of improving the interaction through human resource management. To a large extent, Sundaram and Webster (2000) contend, firms can assure quality in the hospitality industry, for instance, by training and motivating frontline employees to treat customers respectfully.

In considering the link between service quality at the point of the encounter between frontline staff and the guest and the management environment within companies, Mansfield (1990) notes that customer care starts at the top, meaning 
that commitment to the principle of customer care must emanate from senior management levels within an organisation. She argues that customer care involves everyone in the organisation. Whilst she sees that as a continuous process, i.e. one that is not a quick fix process, Mansfield stresses that improving the lot of staff encourages a better service and better experience for customers. Invariably, this development impacts on customers as workers are able to redirect their energies into doing what is expected of them and also in fulfilment of their desires. Clearly, this situation finds expression in the two studies that form the basis of this paper.

From the point of view of hospitality management, staff has a strategic position in view of their positioning in the "moment of truth" (Sarpong 2007). Their ability to exceed customer's expectations would be paramount for the competitive advantage of their organisations. As a consequence, employee job satisfaction is crucial and often linked to organisational commitment which, in turn, leads to service effort (Testa 2001). Arnett et al. (2002: 88) has emphasised that "job satisfaction and pride in the organisation result in an increase in positive employee behaviour". They maintain that positive employee behaviour is characterised by commitment to providing the guest with good service, cooperation with other employees and a commitment to the organisation.

The conceptual basis for this analysis is that the relationship between guests and hotel staff develops as a result of the service encounters they engage in. The growth of the service society has brought about an increase in service encounters. Service encounters have also increased in importance as competition between companies has become tougher. Much attention has been given to the structure of this type of interaction as it has been acknowledged that the customer's perception of the encounter, to a great extent, determines the quality perception of the service (Ling et al. 2010). For instance, how the employee treats customers and accommodates their needs can be decisive for the outcome. By the same token, the design of the service process affects the outcome in a specific way.

In recognition of the immense challenges facing the hotel sector, it seems hotels need develop a model that recognises the creation of a unique corporate culture to effectively drive an organisation's values, mission and philosophy. Such a model should be based on the premise that having satisfied employees translates to satisfied customers and more value creation. Though a number of hotels are now striving to keep pace with changing trends, in order to provide complete customer satisfaction, the needs and expectations of the customer need to be fully understood (Hellriegel et al. 1998). According to Gilmore and Pine (2002), the key to creating memorable encounters lies not in improving the functionality of a service but rather in layering an enjoyable experience on top of an existing service.

This calls for the pursuit of rudiments like reliability, responsiveness, assurance, empathy among others. These are virtues that ought to be imbibed in hotel employees as they strive to win customers in a bid to survive the vigorous competition within the industry. The need to address gaps in service encounters has also become very paramount. Hence, a service provider's behaviour at the 
point of delivery may influence consumer expectations toward the service offering (Coye 2004).

It is most likely that a great deal of customer satisfaction would be realised where front-line staff are empowered to take decisions in the best interest of the organisation, especially on the spur of the moment. Those whose job it is to create customer satisfaction in this situation must have both the authority and confidence to do this (Sarpong 2007). They need to cultivate those key interactions that do create value in a service by meeting and exceeding expectations. It is also important to listen to customers and act on their request and feedback. Staff should be trained to listen empathetically; work together towards a satisfactory solution, commit the company's full resources to achieving the desired outcome and follow up to ensure any problem is resolved to customer's satisfaction.

Staff empowerment, which has already been alluded to, will help to remove the barriers in organisations that constrain performance (Geralis and Terziovski 2003). But, front-line staff still needs guidance, direction and support. Given these, they can assume the full responsibility in satisfying the customers they serve, by making a strong contribution to the performance of the whole organisation's business. In order to be able to do this effectively, employees themselves need to know what is going on. They need to have a shared understanding of what the organisation is trying to achieve. Employees play an important role in keeping customers informed about what is happening in the system. Therefore, they need to be knowledgeable about their organisations as well as being able to demonstrate a wide range of interpersonal skills in order to be able to respond appropriately.

The truth, however, is that, achieving profitable, organic growth is never simple. New industry dynamics, changing customer demographics and other factors present considerable challenges to establishing the loyal customer relationships that are the foundation of growth. It appears the clear winners in the future will be a hotel management which is truly committed to customer satisfaction, value and consistent provision of the basic lodging fundamentals. Furthermore having a swift, friendly check-in, with all the information being correct the first time, solves many problems and greatly improves customer satisfaction (Lewis and Chambers 2000).

Staff should be encouraged to continue treating guests as special people. There is also the need for staff recognition programmes for exceptional guest service, including rewards. Besides, companies should endeavour to hire employees who share their values, where possible. Strong cultures correlate with corporate success (Sarpong 2007). Hence, a strong organisational culture significantly would increase the potential for fast responses that are considered necessary in a rapidly changing responsibility.

Incidentally, service quality, the ultimate direction for service encounters, cannot be objectively measured as in the case of manufactured goods and, it therefore, remains a relatively elusive and abstract construct (Zeithaml et al. 1990). Evaluating quality for services is more complex because of service's intrinsic nature of heterogeneity, inseparability of production and consumption, 
perishability and intangibility (Frochot and Hughes 2000). In the hotel industry, other attributes such as imprecise standards, short distribution channel, reliability and consistency, face to face interaction and information exchange and fluctuating demand have been identified and further complicate the task of defining, delivering and measuring service quality. Besides, as Mei et al. (1999) note demand for service in the hotel industry is generally made around peak periods such that check-in, check-out times or holiday season and those peak periods usually create an environment which makes it difficult to provide consistent service quality.

In spite of the above, efforts still need to be made to locate and analyse examples of best practice in service businesses (Sarpong 2007, Baron and Harris 1995). Models of successful service businesses which offer a range of products and services could be used to guide operations of other providers. The fundamental question of what makes the "ideal" or "best" service business still needs to be answered though.

\section{Conclusions}

The main purpose of this paper was to examine the unique challenges of the "moment of truth" and the way they are managed. Another objective was to establish elements of service quality that are likely to be instrumental in the face to face experience with customers. The paper also looked at the ways at meeting customer demands in the hotels and explained the basic issues that confront hotel operations. It also explored the patterns of structure, management and organisational development that are needed to achieve service objectives. It, therefore, identified and developed an approach to management that sought to achieve new objectives with a greater consistency of both internal and external relationships. In addressing the concept of "moment of truth" the paper proposed effective measures for improving service encounters for participants of the encounter. This was meant to assist them to recognise and formalise each other's behaviour and expectation.

\section{References}

Albrecht K (1988) At America's Service - How Corporations can Revolutionise the Way they Treat their Customers. Homewood, IL: Dow Jones-Irwin.

Albrecht C, Zemke R (1985) Service America: Doing Business in the new Economy. Homewood, IL: Dow Jones -Irwin.

Arnett DB, Laverie DA, McLane C (2002) Using job satisfaction and pride as internal-marketing tools. Cornell Hotel and Restaurant Administration Quarterly 43(2): 87-96.

Baron S, Harris K (1995) Services Marketing - Text and Cases. Hampshire: Macmillan Press Ltd.

Baum T (1997) Making and Breaking the Tourist Experience. In C Ryan (Eds) The Tourist Experience - A New Introduction. London: Cassell. 
Baum T (2002) Skills and Training for the Hospitality Sector: a review of issues. Journal of Vocational Education and Training 54(3): 343-363.

Bitner MJ (1992) Services capes: the impact of physical surroundings on customers and employees. Journal of Marketing 56(2): 57-71.

Bitner MJ, Booms BH, Tetreault MS (1990) The service encounter: diagnosing favourable and unfavourable incidents. Journal of Marketing 54(2): 71-84.

Bitran, GR, Hoech J (1990) The humanization of service: respect at the moment of truth. Sloan Management Review 31(2): 89-96.

Bitran G, Lojo M (1993) A framework for analysing the quality of the customer interface. European Management Journal 11(4): 385-396.

Blomqvist R, Dahl J, Haeger T (2002) Customer Relationship Development. Kent: Financial World Publishing.

Bradley GL, McColl-Kennedy JR, Sparks BA, Jimmieson NL, Zapf D (2010) Service encounter needs theory: a dyadic, psychosocial approach to understanding service encounters. In WJ Zerbe, EJ Härtel Charmine, NM Ashkanasy (Eds) Emotions and Organizational Dynamism (Research on Emotion in Organizations) Volume 6: 221-258. Bingley, UK: Emerald Group Publishing.

Carlzon J (1987) Moments of Truth. Cambridge, MA: Ballinger.

Cowell D (1984) The Marketing of Services. London: Heinemann.

Coye RW (2004) Managing customer expectations in the service encounter. International Journal of Service Industry Management 15(1): 54-71.

Czepiel JA (1990) Service encounters and service relationships: implications for research. Journal of Business Research 20(1): 13-21.

Czepiel JA, Solomon MR, Surprenant CF, Gutman EG (1985) Service encounters: an overview. In JA Czepiel, MR Solomon, CF Surprenant (Eds) The Service Encounter-Managing Employee/Customer Interaction in Service Businesses, pp.: 3-15. Lexington, MA: Lexington Books.

Ekinci Y, Dawes PL, Massey GR (2008) An extended model of the antecedents and consequences of consumer satisfaction for hospitality services. European Journal of Marketing 42(1/2): 35-68.

Francois J, Hoekman B (2010) Services Trade and Policy. Journal of Economic Literature 48(3): 642-92.

Frochot I, Hughes H (2000) Histoqual: the development of a historic houses assessment scale. Tourism Management 21(2): 157-167.

Geralis M, Terziovski M (2003) A quantitative analysis of the relationship between empowerment practices and service quality outcomes. Total Quality Management and Business Excellence 14(1): 45-59.

Gilmore JH, Pine BJ (2002) Customer experience places: the new offering frontier. Strategy and Leadership 30(4): 4-11.

Global Services Forum (2013) Services: A New Frontier for Sustainable Development. UNCTAD and OECD.

Gronroos C (1990) Service Management and Marketing. Lexington, MA: Lexington Books.

Hartline MD, Woolridge BR, Jones KC (2003) Guest perceptions of hotel quality: determining which employee groups count most. Cornell Hotel and Restaurant Administration Quarterly 44(1): 43-52.

Hellriegel D, Slocum J, Woodman R (1998) Organisational Behaviour $\left(8^{\text {th }}\right.$ edition). Cincinnati, Ohio: South-Western College Publishing.

India Brand Equity Foundation (2016) Service Sector in India. Retrieved from http://goo.gl/W2JHsl. [Accessed: 22 February 2016] 
Irons K (1994) Managing Service Companies - Strategies for Success. Wokingham: Addison Wesley Publishing Company.

Juwaheer TD (2004) Exploring international tourists' perceptions of hotel operations by using a modified SERVQUAL approach: a case of Mauritius. Managing Service Quality 14(5): 350-364.

Kelley SW (1993) Discretion and the service employee. Journal of Retailing 69(1): 104-126.

Kotler P, Bowen J, Makens J (2003) Marketing for Hospitality and Tourism $\left(3^{\text {rd }}\right.$ edition). Upper Saddle River, NJ: Prentice-Hall.

Lewis BR, McCann P (2004) Service failure and recovery: evidence from the hotel industry. International Journal of Contemporary Hospitality Management 16(1): 6-17.

Lewis RC, Chambers RE (2000) Marketing Leadership in Hospitality Foundations and Practices ( ${ }^{\text {rd }}$ edition). New York: John Wiley and Sons.

Lilja J, Wiklund H (2006) Obstacles to the creation of attractive quality. The TQM Magazine 18(1): 55-66.

Ling KC, Piew TH, Chai, LT (2010) The impact of resource input model of education quality on the overall students perceived service quality. Canadian Social Science 6(2): 125-144.

Lovelock C, Wright L (2002) Principles of Service Marketing and Management $\left(2^{\text {nd }}\right.$ edition). Upper Saddle River, NR: Prentice Hall.

Mahesh VS (1988) Effective human resource management: key to excellence in service organisations. Vikalpa 13(4): 9-15.

Mansfield S (1990) Customer care in tourism and leisure, Insights. London: The English Tourist Board.

Mei AWO, Dean AM, White CJ (1999) Analysing service quality in the hospitality industry. Managing Service Quality 9(2): 136-143.

Meyer C, Schwager A (2007) Understanding customer experience. Harvard Business Review 85(2): 116-126.

Morrar R (2014) Innovation in services: a literature review. Technology Innovation Management Review 4(4): 6-14.

Normann R (1984) Service Management. New York: John Wiley.

Paraskevas A (2001) Internal service encounters in hotels: an empirical study. International Journal of Contemporary Hospitality Management 13(6): 285-292.

Parasuraman A, Zeithaml VA, Berry LL (1988) SERVQUAL: a multiple-item scale for measuring consumer perceptions of service quality. Journal of Retailing 64(1): $12-40$.

Payne A, Christopher M, Clark M, Peck H (2003) Relationship Marketing for Competitive Advantage - Winning and Keeping Customers. Oxford: ButterworthHeinemann.

Pullman ME, Gross MA (2004) Ability of experience design elements to elicit emotions and loyalty behaviours. Decision Sciences 35(3): 551-578.

Sarpong S (2007) Welsh Hotels and Their Moment of Truth. Unpublished MA dissertation submitted to the University of Wales, Newport, UK.

Sarpong S (2015) Is Customer Care Elusive? Accra: Epitome Publications (forthcoming).

Schneider B, Bowen DE (1993) The service organisation: human resources management is crucial. Organizational Dynamics 21(4): 39-52.

Scott N, Laws E, Boksberger P (2009) The marketing of hospitality and leisure experiences. Journal of Hospitality Marketing \& Management 18(2-3): 99-110. 
Smith I (2003) Meeting Customer Needs ( $3^{\text {rd }}$ edition). Oxford: ButterworthHeinemann.

Smith S, Wheeler J (2002) Managing the Customer Experience: Turning Customers into Advocates. London: Financial Times Prentice Hall.

Söderlund M, Julander CR (2006) Physical Attractiveness of the Service Worker and its Effects on the Customer in the Moment of Truth. Paper presented at the $5^{\text {th }}$ International ECR Research Symposium, Stockholm University, Sweden, 14-15 September 2006.

Strauss B, Mang P (1999) Culture Shocks' in inter-cultural service encounters? Journal of Service Marketing 13(4/5): 329-346.

Sundaram D, Webster C (2000) The role of nonverbal communication in service encounters. Journal of Services Marketing 14(5): 378-391.

Testa MR (2001) Organisational commitment, job satisfaction and effort in the service environment. The Journal of Psychology 135(2): 226-236.

Walls A, Wang YR, Okumus F, Kwun DJW (2009) Experiential consumption - a guest's perspective - a luxury hotel segment study. Paper presented at the 14th Annual Graduate Student Research Conference in Hospitality and Tourism, Las Vegas, 4-6 January 2016.

Whiteley R (1991) The Customer Driven Company: Moving From Talk to Action. London: Business Books Ltd.

Winstead KF (2000) Services behaviours that lead to satisfied customers. European Journal of Marketing 34(3/4): 399-417.

Woodruffe H (1995) Services Marketing. London, UK: M \& E Pitman Publishing.

Zeithaml VA, Bitner MJ (2003) Service Marketing. New York: McGraw-Hill.

Zeithaml VA, Parasuraman A, Berry LL (1990) Delivering Quality Service: Balancing Customer Perceptions and Expectations. New York: The Free Press. 